it has since been removed. "We're going to let things calm down for at least a few weeks before

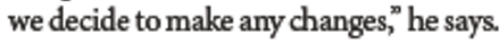

One thing that particularly irks critics is the way the decision was made. The IAU has nearly 9,000 members, but only 2,500 people attended the Prague meeting and only a fewhundred were present for the vote. The IAU should have used the Internet to gauge wider opinion, and then allowed electronic voting, according to those who oppose the definition.

"The IAU seems to be rooted in the preInternet age," says Mark Sykes, director of the Planetary Science Institute in Tucson, Arizona, who instigated the petition. "The rules of the IAU say that resolutions are passed by those present and voting," says Catherine Cesarsky, director of the European Southern Observatory and newly elected president of the IAU.

Sykes admits that a "better definition" might be hard to come by, but is still pressing for the current one to be scrapped. He thinks the IAU would be better off without any definition at all rather than the one they have chosen. "If they can determine that this process was flawed and nullify it, then I think that would be in their best interests, he says.

"If enough people are completely unhappy, we could go through the process again," says Ekers. But a new resolution would have to wait for the next general assemblyin 2009 in Rio de Janeiro. The IAU may issue a clarifying statement in the next week or two, but is hesitating to do so now. "Perhaps we need to make our next statement when things are a little less emotional," says Ekers.

Jenny Hogan

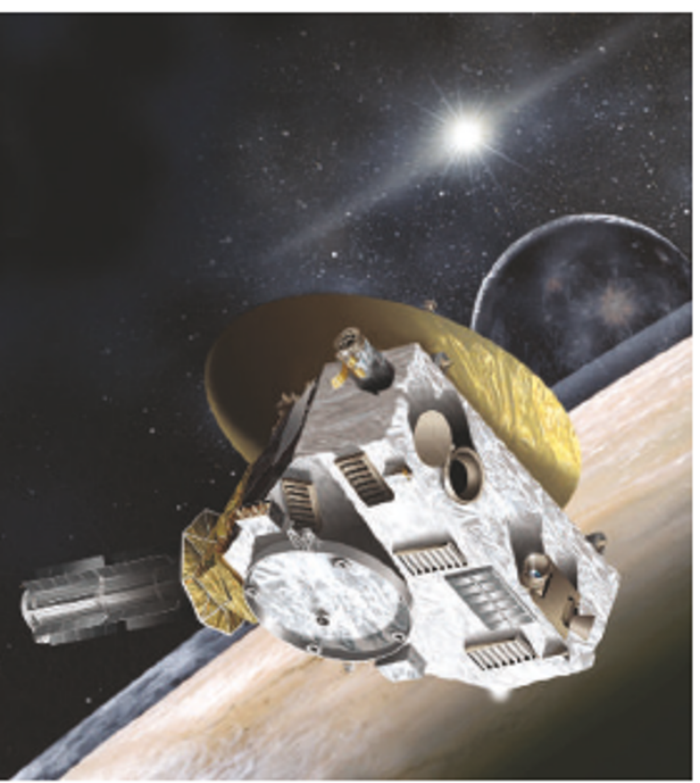

NASA's NewHorizons probe should reach Pluto in 2015, regardless of whether it is still a planet.

\title{
Diary of a planet's demise
}

\author{
While attending the International Astronomical Union's meeting in \\ Prague, Jenny Hogan kept the world up to date on the Pluto debate \\ through our newsblog. Edited excerpts:
}

\section{Monday 21 August}

The proposal to define a planet as anything round that isn't a moon, and thus increase the tally in our Solar System to 12, is scheduled for discussion at lunchtime tomorrow. But many astronomers have already conveyed their objections to the executive committee of the International Astronomical Union (IAU) by e-mail — and some are supporting a second, rival definition.

This alternative definition argues that a planet, as well as being round, must also be «by far the largest object in its local population". This definition knocks Pluto off its planetary pedestal (although it offers it concessionary 'dwarf planet' status), and destroys the chances of promotion for Ceres, queen of the asteroid belt.

Of the 100 people in the closed meeting last Friday where the alternative definition was floated, a show of hands showed about 50 for it and only 20 for the IAU's suggestion.

23:00 My dinner companions tonight include some (very tired) members of the Planet Definition Committee. They say they have received hundreds of e-mails over the past few days from geologists complaining about the proposal in the original definition to use 'pluton' to mean an object in the same class as Pluto. Pluton is a term of long-standing and wide use in geology, where it refers to an intrusion of igneous rock.

Another problem has emerged in translation. The French name for Pluto is - you've guessed it - Pluton. The definition committee thought this linguistic borrowing would give the pluton label special appeal for French-speaking astronomers, but apparently some of them object.

All this leads to speculation that tomorrow's revised definition, whatever other changes it contains, will include a replacement word for 'pluton'

\section{Tuesday 22 August}

15:00 For people who often tell journalists that defining a planet is a meaningless labelling exercise, astronomers actually seem to care a great deal. The open discussion on what makes a planet stopped just short of fisticuffs.

The official resolution has been divided into three parts, each of which will be voted on separately on Thursday at the closing ceremony. These cover the requirement of roundness, the distinction between a binary planet

\section{Dwarf planet in quotes}

"I'mhere I'm asphere.

Get used to it."

Pluto itself, talking to Gady Epstein of the Baltimare Sun about its recent demotion.

\section{"Idon't know about the public, but.... the as trologers will beupset." \\ PatrickMoore, astronomer and veteran presenter of the BBC's The Sky at Night.}

\section{“Pleasedon't turn Pluto into ad warf planet because that makes me sad. I'll miss Pluto a lot." \\ Daniel Dauber, aged six, on Nature's Newsblog,}

"This is as if botanists had found something between trees and bushes and invented the word 'animal' to describe it."

Allen Glazner of the University of North Carolina, Chapel Hill, on the proposal to call dwarf planets 'plutons' - a term that geologists have long used to describe certain bodies of rock.

"Since the term is not in
the Microsoft Word or
Word Perfect spellcheckers,
we thought it was not that
common."
Owen Gingerich, chairman
of the Planet Definition
Committee, which proposed
the use of thetermpluton.

"The comments were intelligent, but they came with apassion that makes me thinkthis debate has a non-intelligent dimension." Paul Murdin, Cambridge astronomer, at the annual meeting of the International Astronomical Union.

"It's over, it's done." Richard Binzel, an astronomer at the Massachusetts Institute of Technology and member of the Planet Definition Committee, on the Prague vote.

Sources: Baltimore Sun, Guardian, Nature, news@nature. 
and a planet-moon system; and the naming of Pluto-like objects.

Within seconds of comments being invited, queues form at the microphones. One by one, astronomers denounce the definition in tones ranging from offended to furious. The representatives of the Planet Definition Committee slump into their chairs, heads propped on their hands.

Andrea Milani of the University of Pisa is first to reach a microphone. He articulates the concerns of the 'dynamicists' - astronomers interested in orbits, many of whom feel strongly that the condition of dominating an orbital zone should be a central part of the definition. Milani becomes more incensed as he speaks, ending by saying " your paper is a kind of offence to the entire dynamical community".

Meanwhile, those who work on extrasolar planets - some with many times the mass of Jupiter - feel that their field has been neglected. Why does the definition not set an upper mass limit? As this point was raised again and again, IAU president Ron Ekers became more and more frustrated. ${ }^{\alpha}$ We want your input, but not right now," he eventually snapped.

17:30 We are now on version three of the planet definition. I was expecting another lively show of dissent - but it is not to be, thanks to Jocelyn Bell Burnell, the astronomer who discovered the first pulsar. A member of the IAU's resolution committee, which decides what gets voted on, she takes formidable control of the meeting. With only 45 minutes available, she requires comments to be no more than

"Your paper is a kind of offence to the entire dynamical community".

putting Pluto and other round trans-neptunian snowballs into a 'plutonian object' category. “Only minor corrections can be accommodated at this stage," the paper warns.

11:30 I'm skipping down the stairs of the conference centre on my way to a 10.30 interview (not about planets) when I encounter a charge of scientists led by the esteemed Brian Marsden. "You're the press," one of his cohort notices. "Show us to the press room."

I retrace my steps. Marsden has, for many years, been the head of the Minor Planet Center at Harvard, a clearing house for orbital data on asteroids and comets. (This week's redefinitions are set to turn them into 'small Solar-System bodies'.) Today marks his retirement, but he enters the press room with youthful vigour.

He holds up an A4 sheet of 'elevator pitches' - sold in the time it takes a lift to travel one floor. The astronomers meekly follow her orders.

The latest version requires that a planet be both round and, at the insistence of the dynamicists, dominant. Round objects that don't dominate their local orbital zone are 'dwarf planets'. Bell Burnell spells out the consequences: "This means that Pluto is a dwarf planet, but it is not a planet." Would that be acceptable to the assembled astronomers?

It seems so. In a quick show of hands, more arms are raised in favour than against.

\section{Thursday 24 August}

The final text of the resolution (version four by my count) is posted in today's edition of the conference newspaper Nuncio Sidereo III. According to this resolution, the Solar System has eight top-flight planets, with Pluto in a second class of dwarf planets. Separate votes will be held on whether to label these top-flight planets 'classical planets' and what, if anything, to do about paper, on which is written in very large letters the word 'Planetino'. 'Planetino is what they say in the resolution is a dwarf planet," he proclaims.

Pointing to the ten or so astronomers straggling in behind him, Marsden says his proposal to call 'dwarf planets' 'planetinos' instead has support from representatives of Uruguay, Brazil, the Czech Republic, the Netherlands, Norway, Serbia and the United Kingdom - at least. The press room descends into a hubbub as reporters grab their notepads or leap to their laptops. The press officers trying to run the show look on, bemused.

13:50 Just before the closing ceremony starts, a television crew searches for a miserable American. Pluto, after all, was discovered at the Lowell Observatory in Flagstaff, Arizona, by the American Clyde Tombaugh. The search so far seems to have been fruitless. But I do see someone waving a picture of Pluto the Disney dog somewhere near the front...

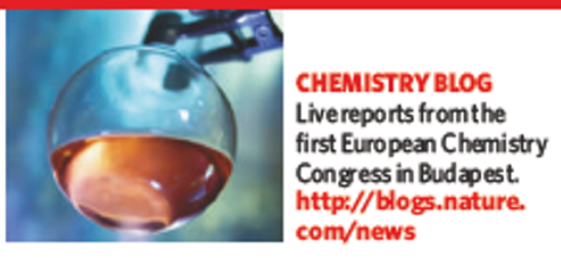
first European Chemistry Congress in Budapest com/news

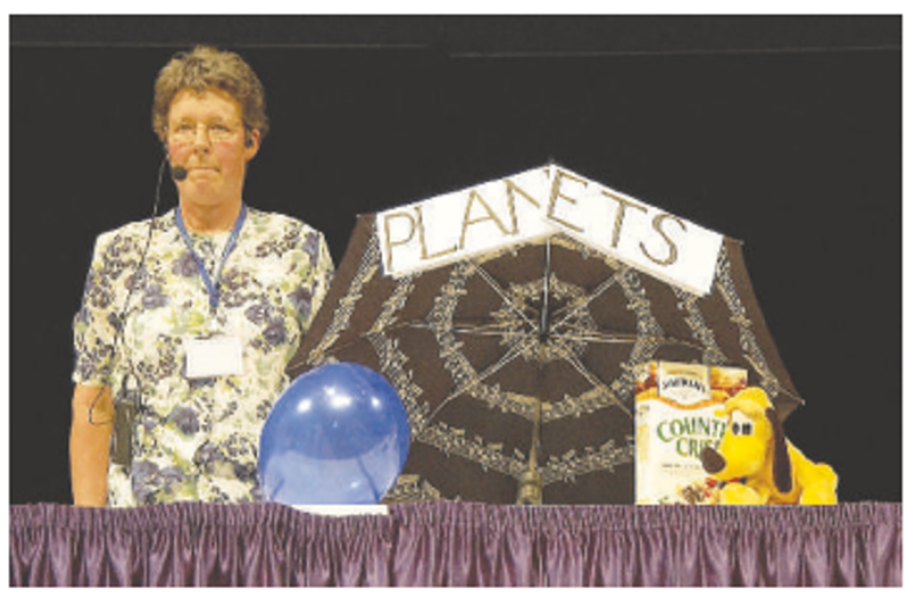

Moment of truth: Jocelyn Bell Burnell uses props to liven up the voting on whether Pluto is a planet.

14:35 "You will need a pen or a pencil," says Bell Burnell, who is chairing the session. The audience duly rummages in its bags, in order to add inverted commas to the category 'dwarf planets' and clarify the situation over satellites.

A speaker from the floor suggests, to much laughter, dropping all the resolutions except footnote 1 to $5 \mathrm{~A}:{ }^{\alpha}$ The eight classical planets are: Mercury, Venus, Earth, Mars, Jupiter, Saturn, Uranus and Neptune.

14:43 At last, the vote. Astronomers wave little yellow cards in the air to indicate their support for resolution $5 \mathrm{~A}$ - that's the one that recognizes three categories of object: planets, 'dwarf planets' and small Solar-System bodies. A few people wave their cards to vote the resolution down, a few abstain.

A moment's hesitation from the chair. Then: "I believe the resolution is clearly carried."

Amazing! A decision! I wouldn't have predicted that at the week's beginning.

Bell Burnell brings out teaching aids from under the table. A blue balloon to represent the planets. A stuffed Disney Pluto and a box of cereal (Ceres, therefore cereal, get it?) stand in for the 'dwarf planets.' There's something indistinguishable and lumpy for the small Solar-System bodies.

Next, a vote on resolution $5 B$. Are classical planets and 'dwarf planets' all planets proper, giving us two classes of planets and making 'planet' an umbrella term? (Out comes an umbrella labelled 'planets.') Ninety-one in favour. The number against is overwhelming - no need to count again.

"It's clear that resolution 5B is not passed," the chair reports. So, we have eight planets only. Pluto is out.

Straight after the vote, I see Richard Binzel of the Massachusetts Institute of Technology, a member of the Planet Definition Committee. He says, with some relief, "it's over, it's done."

Oh no it's not. 